\title{
Reply to John Landon's Position Paper
}

Arlene Stairs

\section{The Professional Development of Native Educators: Context, Culture, and Language}

I am fortunate that my experiences in Canadian Native education include one exceptionally hopeful situation which is evolving strongly towards the mainstream and nonassimilative Native education model proposed by John Landon. The Inuit of Arctic Quebec provide this example of exceptional progress; an example which must be related to two unique historical-cultural circumstances as well as to the will and effort of educators and the population. First, Inuit in Arctic Quebec maintain the highest level of Native language use in Canada, including an Inuktitut basic literacy rate of close to $100 \%$ (Stairs 1985). Relative geographic and economic isolation, and the fact that Quebec has two competing nonNative languages, are among the factors cited to explain such high Native language viability. Second, Native negotiation with eastern North America's demand for electricity led to the James Bay and Northern Quebec Agreement of 1976, which has been responsible for Inuit political and economic control over their school system for the last 10 years. Very significantly, this control includes the education of their own Native teachers to full provincial and university certification.

The Quebec Inuit situation adds to or modifies some of the Native teacher education options described by John Landon. The following briefly describes ongoing developments in Inuit Quebec. Quebec Inuit illustrate the extremely broad range of cultural and linguistic contexts in Native education situations - a point to which I will return in closing.

I hope that on another occasion Inuit educators can confer with you personally on the following teacher education issues. I am unused to and reluctant to report on Inuit education in the absence of my Inuit colleagues. Unfortunately however, no eastern Arctic Inuit could be here for this Forum since they are in the midst of summer teacher education sessions on Hudson Bay and Baffin Island.

\section{Selection of Native teachers and entry into teacher education programs.}

In Quebec Inuit settlements teacher trainees are selected by local education committees. The problem for teacher educators then becomes how to respond to the selected Native teachers' professional development needs, rather than how to design a teacher education program and its selection 
criteria. Once chosen and at work (with the support of pedagogical counsellors), Inuit teachers are required to attend training courses, given in various villages, until fully certified.

\section{Native instruction in Native teacher education.}

Teacher education in Arctic Quebec is carried out in Inuktitut through a variety of stepwise trainer-trainee collaborations. Initially, "mini-course" planning sessions take place in English involving Inuit instructors and academic consultants, usually not fluent in Inuktitut. At later stages Inuit instructors present courses in Inuktitut independently, incorporating relevant content and teaching processes emerging from previous sessions. Currently, post-certification degree-level courses are being pursued through a two-step tutorial system. Interested students are helped to find an academic tutor in their field of interest. After one three-credit segment, tutor and tutee then teach the course bilingually (Inuktitut and English) to the full group of Inuit teachers at degree level.

\section{Curriculum and development in Native teacher education.}

In the developmental phases of this Native-directed teacher education, it has been impossible to offer a standard set of courses with a range of options. Everyone is involved in the evolution of both the school system and the teacher education program, with material and curriculum development an integral part of most training courses. Individual differences in background (e.g., bilingual or not, experience in or outside schools) are respected and used within the same basic certificate courses for all. With time, specialized courses are added to the base as Inuit educators begin to specialize or, as now, some begin teaching in English.

\section{Complex roles of Native teachers and implications for teacher education.}

Native teachers have a dual role often unrecognized by teacher trainers a role which is both educative and sociocultural. Inuit and other Native educators describe their jobs as, to some degree, a "calling", arising from home and community. While non-Native teachers identify primarily with the school and work towards bringing the community into the school, Native teachers identify with their community and its goals and work to bring the school into the community. There is a continual sense of urgency both to provide teaching by trained educators as promptly as possible, and to push back external domination of educational development including teacher education. These role demands are best met by a continuing work-integrated and field-based style of teacher education. Many Inuit educators cycle over a period of several years from classroom teacher, to teacher-education instructor or regional consultant, to mother and non-professional community member, and back to the classroom. 
Arctic Quebec success so far with this highly contextualized process in Native teacher education raises the issue of whether teachers need leave their communities and attend a mainstream university, learning and studying in a second language, to become well-qualified without lowering standards. This can be a hotly debated issue, and probably alternatives are necessary. As of a few weeks ago, there are now two Inuit Bachelor of Education graduates in Quebec who never attended university full-time or in the South. Both are specialists working in both Inuktitut and English.

5. Relationships of non-Native educators to Native teacher education. The pattern of Native education being described has implications for the roles of all non-Native specialists. This is especially true for linguists, who often feel their work is preliminary to any development of Native education. In the quickly evolving Quebec Inuit situation, it is often the experienced Native teacher, rather than or in collaboration with the linguist, who has the last word on materials, student evaluation, or terms used in teacher training courses. As both student and teacher programs evolve, non-Native consultants continually step back as Inuit take on and reform educational specialist roles.

Both Native and non-Native teachers have remarked that all educators can benefit from Native teacher education. For mainstream teachers, the Native focus has stimulated multicultural awareness and a sense of alternatives in teaching-learning styles and in the value priorities of formal education settings. Among these alternatives demonstrated through Native education are a) group rather than individual achievement, b) indirect situational instruction, c) reality-testing (i.e., via feedback from physical and social environments) versus teacher-mediated evaluation and discipline, and d) experience-related and efficient use of language.

\section{Evaluation of Native teacher education in relation to student language learning.}

We must ask if all these developments are working in terms of student success. Recently compiled results of a two-year Inuktitut/English study show changes since studies of several years ago. In the 1970s, children gradually lost first language skills as they progressed through school, but they also remained weak in second language. Today, with the first cohort of students taught early by trained Inuit teachers, we see that those stronger in Inuktitut in early primary years are also more successful in their second language a few years later.

Many questions, however, surround each evaluations. First, in English, the focus for comparison with other studies are CALP* skills, usually written, towards the end of elementary school. One can question whether 
there may not be some differences in the CALP/BICS* distinction in Native cultures with highly developed oral 'literacies', and we know from recent work in teacher training courses that language development patterns in Inuktitut differ from those in English. Furthermore, first language maintenance is as much a concern here as second language acquisition. Beyond language learning, lowered dropout rates and overall educational and life success will become increasingly important criteria.

\section{Cultural goals, school roles, and Native teacher education.}

In Native education, the area of language awareness as discussed by John Landon is often buried in the whole personal and cultural question of identity, values, and survival. Divergent views concerning the path to cultural survivial focus sharply on the role of the schools in Inuit society, and particularly on language policy within the schools as reflective of survival strategy.

At one extreme are those who emphasize economic survival and see the schools' primary responsibility as providing skills for competition on the terms of mainstream southern society. This group favours essentially second-language education at all levels, claiming that Arctic Quebec Inuit culture outside the schools is sufficiently intact not to be threatened by mainstream Canadian education, and that Inuktitut is sufficiently strong not to require formal instruction. At the other extreme are those who emphasize ideational survival: cultural survival based on Inuit values, thought and social models. This group favours full first-language education at primary levels, with continuing and expanding use of Inuktitut at higher levels, pointing to the rapid language loss experienced in other apparently sound Native language situations (major loss in as little as one generation in parts of the western Arctic and nearby Labrador). This group and many between the two extreme views claim that effective learning for Quebec Inuit, given their still viable first-language social context, rests on a strong base of Inuk identity and the language which represents it (see Bullivant 1984 concerning economic versus ideational cultural survival).

Clearly the changing balance on this issue immediately affects the jobs and training of Native teachers. In northern Quebec the issue of language policy is so crucial to the continued survival of the groups, that the results of systematic studies, from the region or elsewhere, do little to change convictions. Most difficult and anti-intuitive, for instance, is for parents concerned primarily with English competence to accept that early Inuktitut competence will help and not hinder. Trained Inuit educators are often caught in this debate as defenders of first-language instruction and so, apparently, of themselves. 


\section{Collaborative professional development between Native and non-Native teachers.}

The open collaboration so strongly advocated by John Landon might help integrate the inside ideational and outside economic goals of the school. Certainly the teachers in northern Quebec need more such collaboration, especially during transition time into second language around Grade 3. In instances where strong collaboration does exist, it is particularly exciting and useful to the non-Inuit teachers who may never before have known Inuk. There are, however, some special noncollaborative needs in Native education. Native teachers also need to be left alone; to retreat from the stress or intimidation of always being with outsiders; to find their own ways, use their own language professionally as well as in the classroom, and to do their work of building a more Inuit school system.

9. Central roles for Native language in Native teacher education.

Aside from language and cultural content per se, many bilingual Inuit teachers - even those who prefer reading in English - want Inuktitut used in their higher education. They and other Native teachers mention the capacity to think, and to learn cooperatively in a culturally-valued way, as dependent on the use of Native language. I leave you with an Inuk teacher's eloquent statement of this need for professional development based in Native culture and particularly in Native language:

It is very good to have learned English and French, but education is not just learning the language. Our wish is that one's learning leads to where one can do jobs needing thinking and problem solving ... Most of us go as far as having learned the language without reaching our speciality. If trained only in English or French our minds can get lazy because we memorize without thinking.

(Betsy Annabatak, 1985, p. 2)

\section{FOOTNOTE}

* $\quad$ CALP = cognitive/academic language proficiency; BICS = basic interpersonal communication skills (definitions after J. Cummins).

\section{REFERENCES}

Annabatak, B. (1985). Thoughts of an Inuk teacher. Education Express, 1, 2. Bullivant, B. M. (1984). Pluralism: Cultural maintenance and evolution. Avon, England: Multilingual Matters.

Stairs, A. (1985). La viabilité des langues autochtones et le rôle de l'écrit: l'Expérience de l'Inuktitut au Nouveau Québec. Recherches Amérindiennes au Québec, 15, 3. 


\section{THE AUTHOR}

Arlene Stairs is a leading educational development consultant and an adjunct professor at both Concordia and McGill Universities. Dr. Stairs was consultant to the teacher training program for McGill, preparing teachers for schools in Northern Quebec in conjunction with Kativik School Board and for the Northwest Territories in conjunction with Arctic College. She helped establish and gave direction to COPITT, the innovative Child Observation Project Through Inuit Teacher Training in 1979. From this research has evolved a model for educational development in a Native context. Dr. Stairs consults and lectures in Native education in Canada and the U.S.A. and she takes up a position in educational psychology at Queen's University, Kingston in July 1988. 